\title{
COOPERAÇÃO REGIONAL EM SEGURANÇA PÚBLICA: AVALIAÇÃO DO QUADRO NORMATIVO NO CONTEXTO DA UNASUL
}

\author{
Juliana Viggiano ${ }^{1}$
}

\section{Introdução}

O estudo sobre a segurança internacional foi objeto de intensas discussões no ambiente político e acadêmico nas últimas décadas como consequência das transformações sistêmicas ocorridas no cenário internacional iniciadas, efetivamente, na década de 70 e consolidadas com o fim da Guerra Fria. Em especial, os debates buscavam compreender como adequar o instrumental teórico-metodológico da disciplina à natureza dos novos fenômenos de segurança que surgiam como ameaças em um mundo crescentemente interconectado em suas atividades domésticas, intensificando a porosidade das fronteiras nacionais e, por consequência, questionando o significado e as características da guerra interestatal no contexto dessa nova configuração de poder.

Pensar sobre a segurança pública de forma coordenada e comum no plano regional acompanha, com atraso, a iniciativa de se construir políticas públicas regionais em outras áreas, notadamente na área social, de saúde e educação. Muitas outras áreas flertam, com maior ou menor assertividade, com experiências de caráter regional, embora pareça apropriado afirmar que todas ainda se encontram em estágios relativamente iniciais.

Os debates acadêmicos contemporâneos nas Relações Internacionais deixam em aberto dois aspectos instigantes associados à preocupação com a segurança pública regional. $\mathrm{O}$ primeiro diz respeito à introdução sistematizada do âmbito regional como nível de análise dos estudos de segurança

I Professora Adjunta do Departamento de Economia e Relações Internacionais da Universidade Federal de Santa Catarina. Doutora em Ciência Política pela Universidade de São Paulo (USP). E-mail: juliana.viggiano@ufsc.br 
internacional. Tanto na perspectiva dos Complexos Regionais de Segurança (Buzan e Waever 2003) quanto das Comunidades de Segurança (Adler e Barnett I998), para ficarmos com as duas propostas teóricas de maior repercussão, a dimensão regional assume papel prioritário na definição do status de segurança da maior parte dos países do mundo, com as poucas exceções das grandes potências mundiais, cujos interesses são, potencialmente, afetados igualmente por questões regionais e mundiais. A segurança dos Estados, e de suas populações, encontram-se intimamente relacionadas às dinâmicas regionais. Quando se considera a natureza dos fenômenos contemporâneos da ameaça enfrentados pelos países da região Sul-Americana, no entanto, os contornos atribuídos ao conceito de segurança parecem insuficientes. Tradicionalmente, o objeto de estudo da segurança internacional tem como referência a segurança do Estado - de suas funções, população, território e recursos diversos. Portanto, compreender a (in)segurança motivada por instabilidades regionais como aspecto de segurança internacional, sem transgredir a fronteira da ação interna e externa no uso da força, implicava em aceitar a necessidade de securitização das questões de segurança regional - nos termos propostos por Buzan, Waever e de Wilde (I997): elevar por meio da prática discursiva questões da agenda política ao plano da ameaça, autorizando o uso de medidas extraordinárias para resolvê-las. De fato, essa preocupação, tanto com os limites do uso da força quanto da relevância do âmbito regional para a segurança do Estado, motivou em certa medida a militarização, ou a securitização, de temas da agenda regional, em especial, o tráfico de drogas. O que esses quadros conceituais não contemplam é precisamente como lidar com o impacto das dinâmicas de (in)segurança regional nas estruturas da (in)segurança doméstica para além da construção de um discurso que implique em ameaça à sobrevivência do Estado e/ou à violação de fronteiras.

O segundo ponto do debate a merecer atenção refere-se à proeminência das discussões e dos processos acerca da integração regional. A revitalização dos processos de regionalização das relações políticas, econômicas e comerciais, impulsionados pela dissolução dos pilares de estruturação das relações entre os Estados característica da Guerra Fria, acompanhou a intensificação do debate acerca da relevância da dimensão regional nas diversas partes do globo. Não foi diferente na América do Sul. Com um longo histórico na construção de iniciativas direcionadas a promover a integração regional, a década de 1990 assistiu ao florescimento de uma série de novos arranjos cooperativos. Especial ênfase merecem os arranjos sub-regionais do Mercosul e da Comunidade Andina de Nações (CAN). Nos anos 2000, destacam-se a União de Nações Sul-Americanas (UNASUL) e, com menos protagonismo e mais recente em sua criação, a Comunidade dos Estados Latino-Americanos e 
Cooperação Regional em Segurança Pública: avaliação do quadro normativo no contexto da UNASUL

Caribenhos (CELAC). Embora a relevância estratégica e o alcance operacional desses organismos sofram variações de ênfase de governo a governo, pode-se afirmar que esses projetos atendem a interesses compartilhados pelos países da região de criar mecanismos que facilitem a cooperação entre os Estados em diferentes áreas temáticas, influenciem positivamente na redefinição dos termos de inserção global desses países e confiram maior grau de autonomia na condução dos assuntos regionais. Disparidades em termos de recursos, estruturas e objetivos de política externa - e nacional - entre os diversos Estados da região certamente imprimem significados e funções diferentes para esses arranjos no contexto particular de cada um dos agentes que compõem esses blocos, o que faz com que essas afirmações sejam identificadas por cada um dos países sul-americanos com assertividade igualmente distintas.

Por sua diversidade e quantidade, os arranjos cooperativos multilaterais na América do Sul apresentam uma série de sobreposições funcionais e temáticas. Em si, essas convergências não possuem significado positivo ou negativo para a ação coordenada entre os atores regionais; em casos, reforçam ou complementam-se umas as outras (Perrotta 20I6; Hartlapp 20I6). Em termos de abrangência e ambição de propósitos, a UNASUL coloca-se como o ator de maior protagonismo nos processos de cooperação entre os países da América do Sul como um todo. Adicionalmente, estabelece dentre os preceitos normativos de seu Tratado Constitutivo a intenção de criar as bases para a construção de uma cidadania comum regional e, nesse sentido, fomentar o surgimento de mecanismos capazes de garantir o conjunto de obrigações de direitos e deveres associados à mesma.

Especificamente no caso da segurança e defesa, até a criação do Conselho de Defesa Sul-Americano (CDS) da UNASUL em dezembro de 2008, o principal órgão de coordenação política da área no âmbito regional consistia na Conferência dos Ministros da Defesa das Américas, um organismo ligado à Comissão de Segurança Hemisférica da Organização dos Estados Americanos, criado em I995. Com reuniões bianuais e constrangida na definição de objetivos comuns para a região Sul-Americana pela presença dos Estados Unidos, esse Conselho, não obstante, deu início a um histórico de construção de medidas de confiança mútua entre seus países membros, em paralelo a iniciativas bilaterais que ocorriam nesse mesmo sentido entre os Estados da região. O CDS, como de maneira geral à instituição a qual encontra-se vinculada, a UNASUL, propõe-se a estabelecer as bases de uma integração de maior alcance. Além de incentivar o fortalecimento de medidas de confiança mútua entre os países, procura viabilizar o intercâmbio e a cooperação da indústria de defesa, reduzir as assimetrias entre os sistemas de defesa da região, criar uma identidade comum em matéria de defesa e uma visão compartilhada en- 
tre os países da região sobre o tema - vale ressaltar, como proposta normativa (UNASUL 2008b).

Independente dos avanços em direção aos objetivos e princípios gerais estabelecidos em seu estatuto, o CDS tem sido um dos órgãos efetivamente ativos e centrais da atuação da UNASUL. Os debates no âmbito do Conselho geraram alguns desdobramentos institucionais importantes, como a criação do Conselho Sul-Americano em Matéria de Segurança Cidadã, Justiça e Coordenação de Ações contra a Delinquência Organizada Transnacional. Se não podemos aqui afirmar que tal Conselho tenha nascido exclusivamente das preocupações oriundas no CDS, é seguro afirmar que a percepção do Conselho de Defesa Sul-Americano da necessidade de se estabelecer uma distinção clara, em termos conceituais e institucionais, entre segurança e defesa contribuiu para esse desdobramento. O estudo preliminar encomendado pelo CDS ao Centro de Estudos Estratégicos de Defesa, publicado em 20I2, oferece uma distinção conceitual entre defesa e segurança, ressaltando, por um lado, o CDS como lócus inapropriado para se pensar sobre questões de segurança pública, e, por outro, a necessidade de se pensar sobre temas transnacionais, como o tráfico de drogas, a partir perspectiva da segurança pública com coordenação regional, no qual atua o Conselho em Matéria de Segurança Cidadã (UNASUL 20I2b).

Esse artigo tem por objetivo avaliar o quadro normativo da cooperação na área de segurança regional, com especial ênfase às atividades desenvolvidas pelo Conselho Sul-Americano em Matéria de Segurança Cidadã, Justiça e Coordenação de Ações contra a Delinquência Organizada Transnacional (CSSCJDOT), instituição da UNASUL que concentra os esforços nessa questão. A primeira seção do texto discute as diferenças e aproximações entre as concepções de cooperação e políticas públicas, fundamentando a debate na produção sobre políticas públicas regionais, com maior difusão na área social. A segunda parte desse trabalho dedica-se a analisar os documentos produzidos pelo Conselho Sul-Americano em Matéria de Segurança Cidadã, Justiça e Coordenação de Ações contra a Delinquência Organizada Transnacional. A terceira seção, a título de considerações finais, oferece um diagnóstico das limitações, obstáculos e oportunidades identificadas a partir da análise dos documentos no que diz respeito à construção de políticas públicas de segurança regional.

\section{Discussão sobre políticas públicas regionais}

Acompanhando o fenômeno em si, análises sobre políticas públicas 
Cooperação Regional em Segurança Pública: avaliação do quadro normativo no contexto da UNASUL

regionais são bastante recentes. Em parte, a incipiência desse corpo literário resulta do próprio desenvolvimento histórico contemporâneo de políticas dessa natureza, que surgem com o amadurecimento, ou talvez com mais acuidade, com o ajustamento dos processos de integração em se adequarem a demandas de estados e sociedades impactadas pelas transformações desencadeadas pelas dinâmicas da globalização e da ineficiência dos regimes democráticos em oferecer respostas satisfatórias a um conjunto daí oriundas. Por outra parte, o Estado ainda se configura como o lócus privilegiado de produção de políticas. O deslocamento de poder decisório, mesmo que em pequena proporção, para a arena externa esbarra nas dificuldades de construção de consensos e/ou mecanismos institucionalizados de negociação outros quando em referência a instâncias de composição intergovernamental, ou reposicionamento de lealdades cidadã, respaldada por aceitáveis critérios de representação que confiram legitimidade decisória a organismos supranacionais. Portanto, o avanço e aprofundamento da produção de políticas públicas de âmbito regional depende da composição de uma série de fatores, que podem se combinar com forças, formas e ordens distintas: vontade política dos governantes e da burocracia governamental, envolvimento de atores não governamentais, coordenação interagências governamental e intergovernamental e a existência de uma estrutura institucional minimamente estabelecida.

Por certo, a política pública regional, embora nova no sentido mais tradicional do termo 'política pública', encontra convergência com as práticas de cooperação internacional. Amplamente difundida, a cooperação internacional demanda, igualmente, um alto grau de comprometimento e coordenação política. O que se espera é que práticas classificadas como políticas públicas alcancem maior grau de institucionalização, considerando-se a cooperação intergovernamental como uma forma mais branda de atividade política (Yeates 20I4). Nesse sentido, convém compreender como as instituições regionais "contribuem para a regulação e o provimento de políticas públicas" (Bianculli e Hoffmann 20I6, I). No caso das políticas sociais, por exemplo, Yeates (20I4) sugere que as atividades do exercício da política pública sejam categorizadas em redistribuição, regulação e provimento de direitos no nível regional, o que ultrapassaria os propósitos da cooperação.

Diversas definições de políticas públicas foram formuladas desde a criação desse campo de estudos. Souza (2007) resumidamente sugere que algumas perspectivas privilegiam o papel de solução de problemas das políticas públicas, enquanto críticos dessa leitura excessivamente racionalizada da questão enfatizam as dinâmicas de conflito entre ideias e interesses, e de cooperação e compromisso entre governos e outros atores governamentais e não governamentais. De qualquer forma, sugere que "as definições de políti- 
cas públicas, mesmo as minimalistas, guiam nosso olhar para o lócus onde os embates em torno de interesses, preferências e ideias se desenvolvem, isto é, o governo. (...) [A]s definições de políticas públicas assumem, em geral, uma visão holística do tema, uma perspectiva de que o todo é mais importante do que a soma das partes e que indivíduos, instituições, interações, ideologia e interesses contam, mesmo que existam diferenças sobre a importância relativa desses fatores (Souza 2007, cap. 2, posição II35).

Evidentemente, embora seja possível traçar paralelos entre os conflitos de interesses e ideologias entre atores governamentais e intergovernamentais, tratam-se de arenas bastante distintas em termos de dinâmicas decisórias, capacidade de atuação com base em programas e projetos derivados de propostas políticas desenhadas e limitações impostas aos atores envolvidos. Ainda se trata, sem dúvida, de um jogo em duas esferas, que podem ou não serem articuladas simultaneamente. Portanto, o que temos aparentemente em diversas áreas, a segurança pública ainda em seus estágios iniciais na América do Sul, e um pouco mais disseminada na área das políticas sociais, são tentativas intermediárias entre cooperação internacional e política pública. No entanto, as organizações regionais exercem um importante papel de se colocarem como uma instância adicional, potencial ou efetiva, de contestação e conflito político, além de proverem um espaço de coordenação mais permanente entre atores governamentais e não governamentais.

Uma definição de política pública regional, mais restritiva e operacional para o caso de organismos intergovernamentais, foi elaborada por Perrotta $(2016,187)$ :

“[Políticas] públicas regionais [são] as ações e decisões políticas tomadas por organismos governamentais regionais para alcançar objetivos motivados pelo exercício do poder político. Tais poderes políticos são tanto Estados-nação que tenham assinado acordos de integração regional, assim como instituições de governança regional, que podem ou não serem dotadas de autoridade decisória, mas foram auto-executadas. Políticas regionais são resultado da interação complexa de vários atores posicionados em diferentes níveis e escalas de ação e que dispõe de diferentes recursos, interesses, ideiais e valores".

Por esse motivo, uma importante dimensão das análises de políticas públicas regionais recai nos processos de difusão dessas políticas do plano regional para sua adoção no nível governamental (Bianculli e Hoffmann 2016), juntamente com os determinantes para a adoção de políticas. No que diz res- 
Cooperação Regional em Segurança Pública: avaliação do quadro normativo no contexto da UNASUL

peito a instituições de caráter supranacional, como no caso europeu, Radaelli (2003) afirma que as políticas públicas são inicialmente definidas e consolidadas no âmbito da União Europeia, para depois serem absorvidas pelos Estados dela participantes. Não seria, além disso, uma via de mão única: ou seja, no seu processo de constituição, preferências são expostas em complexos processos de negociação no âmbito da União Europeia e, igualmente, os Estados selecionam, dentre um conjunto amplo de opções, as políticas a serem adotadas no nível nacional. As experiências na América do Sul, seja no Mercosul ou na UNASUL, sugerem menor espaço de negociação e de opções políticas para a construção de políticas comuns. Em parte porque o maior envolvimento do âmbito regional nas políticas da esfera nacional acompanha a crescente alocação de competências nos organismos da União Europeia (Hartlapp 20ı6). No caso das instituições sul-americanas, embora haja alguma equivalência se considerarmos os constrangimentos impostos por normas legais produzidas na esfera regional, a distribuição de competências desses organismos é extremamente limitada. A própria estrutura das organizações intergovernamentais, nesse sentido, coloca-se como empecilho na medida em que são fortemente calcadas no executivo dos governos participantes, com pouca autonomia do parlamento quando existente, como no caso do Mercosul ${ }^{2}$.

No entanto, o desenvolvimento institucional dessas organizações, com a criação de organismos especializados em áreas temáticas, de maior ou menor abrangência, aparecem como uma importante evolução na construção de políticas públicas, ou ao menos para instituição de normativas comuns dentro dos setores da política, no Mercosul e na UNASUL. Esse foi o caso, por exemplo, da difusão das políticas de Acreditação e Garantia da Qualidade do ensino superior por intermediação do Setor Educacional do Mercosul (Perrotta 20I6) a instituição do Instituto Social do Mercosul, da Comissão de Coordenação de Ministros e Autoridades Sociais do mesmo organismo, e o Alto Representante do Mercosul, responsável pela Unidade de Participação Social, o Instituto de Políticas Públicas do Mercosul para os Direitos Humanos e o Estatuto da Cidadania, que, coordenados, permitiram a criação do Guia de Ação para a Incorporação da Perspectiva de Gênero nas políticas do Mercosul (Espino 20I6). Em si, não se trata de uma política, mas um quadro de referência importante para o desenvolvimento de políticas de trabalho na região, que embora siga, como regra geral, determinações de ordem doméstica, devem atender a padrões mínimos de regulação estipulados no âmbito do Mercosul: "proibição de trabalho noturno por crianças, [proibição] de trabalho forçado [e] introdução de redes de segurança [para trabalhadores] em todos os Estados-membro" (Hartlapp 20ı6, 96).

2 Para mais detalhes, ver discussão feita por Perrotta (20I6, I88).

72 Austral: Revista Brasileira de Estratégia e Relações Internacionais v.7, n.14, Jul./Dez. 2018 
Assim também ocorreu com o caso da segurança pública no contexto da UNASUL33. Embora o Mercosul tenha se antecipado em inserir a questão da segurança como um tema de interesse comum na região, inicialmente por meio do "Acordo Quadro sobre Cooperação em Matéria de Segurança Regional entre os Estados Partes do Mercosul, a República da Bolívia, a República do Chile, a República da Colômbia, a República do Equador, a República do Peru e a República Bolivariana da Venezuela" 4 , salientando a necessidade de crescente interação e coordenação de ações para lidar com o caráter transnacional dos delitos que afligem os países da regiãos, foi no contexto da UNASUL que se criou um organismo específico para tratar da questão, além de explicitamente abordar o tema da segurança pública ${ }^{6}$. Igualmente, a UNASUL reconhece os desafios comuns impostos pelas ameaças transnacionais. Embora seu tratado constitutivo negligencie mencionar explicitamente a questão em termos de segurança pública, o objetivo específico (q) deixa clara a intenção de se dar tratamento aos assuntos de segurança, sem a preocupação de distingui-los entre propósitos de segurança ou defesa7 ${ }^{7}$ O responsável por ex-

3 No caso do Mercosul, nenhum organismo específico foi determinado para o tratamento das questões de políticas de segurança pública, embora alguns acordos de cooperação dessa natureza tenham sido assinados, como a criação de equipes conjuntas de investigação no combate ao crime organizado, no âmbito do Acordo Quadro de Cooperação entre os Estados Partes do Mercosul e Estados Associados, de agosto de 20 Io.

4 Esse acordo substitui os anteriores "Acordo Quadro sobre Cooperação em Matéria de Segurança Regional entre os Estados Partes do MERCOSUL" e "Acordo Quadro sobre Cooperação em Matéria de Segurança Regional entre os Estados Partes do MERCOSUL, A República da Bolívia e a República do Chile", de 2004.

5 Afirma o documento: "Conscientes de que a crescente dimensão transnacional da ação criminosa implica novos desafios que requerem ações simultâneas, coordenadas e/ou complementares em toda a região, com o fim comum de reduzir ao mínimo possível o impacto negativo desses delitos sobre o povo e sobre a consolidação da democracia no MERCOSUL e Estados Associados" (MERCOSUL 2006, 3) e, em seu Artigo I - Objetivo: O objetivo do presente acordo é otimizar os níveis de segurança da região, promovendo a mais ampla cooperação e assistência recíproca na prevenção e repressão das atividades ilícitas, especialmente as transnacionais (...)" (MERCOSUL 2006, 4) e em seu Artigo 2 - Alcance: A cooperação e assistência mencionadas no artigo anterior serão prestadas, por meio dos organismos competentes das Partes que formulem e implementem políticas ou participem na manutenção da segurança pública e da segurança das pessoas e seus bens, a fim de tornar cada dia mais eficientes as tarefas de prevenção e repressão das atividades ilícitas em todas as suas formas" (MERCOSUL 2006, 4)

6 A próxima seção tratará em mais detalhes o conteúdo dos documentos da UNASUL sobre a matéria.

7 Objetivo específico (q): "a coordenação entre os organismos especializados dos Estados membros, levando em conta as normas internacionais, para fortalecer a luta contra o terrorismo, a corrupção, o problema mundial das drogas, o tráfico de armas pequenas e leves, o crime organizado transnacional e outras ameaças, assim como promover o desarmamento, a não- 

da UNASUL

plicitar a necessidade de se estabelecer uma distinção clara entre propósitos e definições das matérias relativas à segurança pública e à defesa foi o Conselho de Defesa Sul Americano, por meio de relatório encomendado ao Centro de Estudos Estratégicos de Defesa do mesmo, em 20I2. O estudo considera que "[o]s diversos e variados impactos dos delitos transfronteiriços e o incremento da criminalidade organizada têm gerado no âmbito regional uma forte demanda social por melhores níveis de segurança pública" e "não corresponde ao Conselho de Defesa Sul-Americano o tratamento de assuntos de segurança pública", sendo "necessário avançar no estudo de um possível mecanismo de cooperação regional em matéria de Segurança Pública” (UNASUL 20I2). O Conselho Sul-Americano em Matéria de Segurança Cidadã, Justiça e Coordenação de Ações Contra a Delinquência Organizada Transnacional foi criado em 20I2, com a missão de tratar das questões de coordenação de políticas regionais relativas à segurança pública.

Além da institucionalização setorizada, o processo pelo qual uma política passa a ser incorporada por todos os atores membros de um organismo também ocupa papel importante na compreensão do desenvolvimento de políticas públicas regionais. Esse processo de difusão do âmbito regional para o nacional, em uma leitura mais sofisticada, pode ser exercido por mecanismos diretos (coerção, manipulação dos cálculos de utilidade, socialização e persuasão) e indiretos (competição, aprendizado e imitação normativa, todas por parte de quem absorve essas políticas) (Bianculli e Hoffmann 20ı6, I0). A definição de difusão adotada por Bianculli e Hoffmann (20I6, 9), na qual trata-se de um "processo pelo qual ideias e práticas particulares, instituições, regras e regulações se difundem ao longo do tempo e espaço" apesar de reconhecer interdependência no processo, aceita divergências de resultados nas práticas finais dos Estados (ibid.). Isso certamente confere maior flexibilidade para estudar um fenômeno tão incipiente como a produção de políticas públicas regionais, permitindo que se identifique mecanismos e abordagens bastante específicos, de pequeno alcance, como inovações e influência regional. Sua implementação, os atores envolvidos, os recursos disponíveis e os resultados esperados podem variar, embora derivem de uma mesma abordagem sobre a matéria da política. Coloca-se aqui uma questão importante sobre o desenho da política, um aspecto central na definição da política pública, mas abre espaço para compreendermos como a perspectiva regional pode influenciar na convergência de objetivos de políticas públicas entre os governos envolvidos.

Para organismos intergovernamentais que não possuem autoridade supranacional e, portanto, reduzido poder de coerção formal sobre os Esta-

proliferação de armas nucleares e de destruição em massa e a deminagem”. E ainda, objetivo específico (t): "a cooperação para o fortalecimento da segurança cidadã” (UNASUL 2008a, 4).

74 Austral: Revista Brasileira de Estratégia e Relações Internacionais v.7, n.14, Jul./Dez. 2018 
dos-membros, a difusão, portanto, torna-se um aspecto essencial da possibilidade de construção de políticas que possam ser consideradas de caráter regional. Não se trata de um organismo que concentra o poder de decisão e implementação no nível regional, mas sim de um conjunto de políticas comuns, que idealmente compartilham instrumentos normativos e informativos e cooperam operacionalmente para alcançar um propósito comum, elaborado a partir de lutas ideológicas, de interesses e de poder nessas instituições criadas no âmbito regional ${ }^{8}$.

Um elemento fundamental para a ocorrência do processo de difusão de uma política consiste na existência de uma base normativa acordada, capaz de oferecer um direcionamento, um propósito, um objetivo e/ou um mecanismo operativo comum ao tratamento do tema abordado pela política pública. Tratados, protocolos, resoluções, declarações e/ou decisões elaboradas no âmbito regional colocam-se como condições necessárias para a construção de políticas públicas regionais, em paralelo com uma liderança comprometida, clareza quanto a definições e abordagem do problema e articulação da política, em seus objetivos e implementação, com outras agências e arranjos

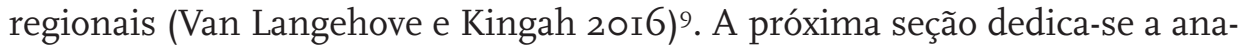
lisar os documentos normativos elaborados pelo Conselho Sul-Americano em matéria de Segurança Cidadã, Justiça e Coordenação de Ações contra a Delinquência Organizada, procurando oferecer subsídios para se pensar os avanços e limitações para a construção de políticas de segurança pública regional.

\section{Previsões normativas do Conselho Sul-Americano em matéria de Segurança Cidadã, Justiça e Coordenação de Ações contra a Delinquência Organizada Transnacional da UNASUL}

Diretamente relacionadas a questões de natureza transnacional no campo da segurança, dois organismos da UNASUL devem ser mencionados. O primeiro consiste no Conselho Sul-Americano em matéria de Segurança Cidadã, Justiça e Coordenação de Ações contra a Delinquência Organizada

8 No caso da política de educação de Acreditação e Garantia da Qualidade de Ensino no Mercosul, por exemplo, incorporada em diferentes graus pelos países membros, o debate regional foi dominado pela Argentina, país mais avançado em termos de cultura acadêmica e arcabouço regulatório, sustentado ainda pelas assimetrias estruturais (Perrotta 20I6)

9 Essas observações foram feitas tomando como base as políticas sociais regionais, mas parece razoável considera-las de forma generalizada como arcabouço mínimo para construção de políticas públicas regionais se aceita-se que as políticas públicas, seja resultado de uma leitura racionalista ou de disputa, atendem a um propósito a partir de certas determinações e limitações conceituais e materiais. 
Cooperação Regional em Segurança Pública: avaliação do quadro normativo no contexto da UNASUL

(CSSCJDOT), e o segundo refere-se ao Conselho Sul-Americano sobre o Problema Mundial das Drogas (CPMD). Conforme será discutido adiante, o CSSCJDOT torna-se protagonista nos assuntos de políticas públicas de segurança, ocupando-se o CPMD de abordar o problema das drogas de uma vertente mais multidisciplinar, que inclui, mas não se limita, aos temas de segurança pública.

O CSSCJDOT foi em criado em 2012 e, em 2013, elaborou um Plano de Ação de 5 anos, com previsão de término prevista, portanto, no ano de 20I7. Trata-se de uma instância permanente de consulta da UNASUL e a discussão realizada nessa parte do artigo teve como suporte os documentos normativos disponibilizados no Repositório Digital da UNASUL ${ }^{\mathrm{I}}$, usando 'seguridad' como termo de busca. Um volume significativo dos documentos encontrados consistem em Atas de reuniões - dos Grupos de Trabalho, da Instância Executiva e das Reuniões de Ministros, complementado por Resoluções, Declarações e Informes. As discussões do Conselho foram divididas em grupos de trabalho - um para Segurança Cidadã, outro para Justiça e um terceiro voltado para Delinquência Organizada Transnacional. As deliberações desses grupos eram subsequentemente remetidas à Instância Executiva do Conselho e, quando apropriado, ao Conselho de Ministros.

Em seu Estatuto de criação, estabelece como princípios “(d) [o] fomento da inclusão social, da participação cidadã e a equidade de gênero, tendo em conta o direito dos cidadãos à segurança e a obrigação do Estado em provê-la" e "(f) [a] coordenação integral no planejamento e execução de ações contra a Delinquência Organizada Transnacional” (UNASUL 20I2a). Em seus objetivos gerais, propõe-se a “(c) promover relações de amizade, confiança e diálogo entre os Estados membros mediante a cooperação regional, integral e coordenada entre as respectivas instituições especializadas com fins de elaborar estratégias conjuntas de política criminal, projetos de cooperação e intercâmbio de informação em matéria de segurança cidadã, justiça e delinquência organizada transnacional"(ibid.). Todas essas ações, afirma ainda o Estatuto, não obliteram a autonomia soberana dos países de definir suas prioridades nas matérias, "assim como para definir políticas e medidas adequadas para fazer frente a estes desafios" (ibid.).

A abrangência das questões tratadas pelo CSSCJDOT se reflete no Plano de Ação elaborado para seus primeiros anos de atuação (20I3-20I7). Ao todo, compõe um quadro com ir eixos temáticos, 32 desafios estratégicos e I37 linhas de ação/objetivos. Em linhas gerais, os eixos temáticos procuram fomentar o fortalecimento das capacidades institucionais dos organismos

Io Disponível em http://docs.unasursg.org/latest-documents, acesso em 24 de novembro de 2017.

76 Austral: Revista Brasileira de Estratégia e Relações Internacionais v.7, n.14, Jul./Dez. 2018 
nacionais envolvidos com as temáticas de segurança cidadã, justiça e delinquência organizada transnacional, além de criar oportunidades para aprimorar a participação cidadã e a atenção aos princípios de direitos humanos nas políticas públicas de segurança e justiça. Procuram equacionar, de acordo com os desafios estratégicos identificados no âmbito do fortalecimento das capacidades institucionais, capacitação dos profissionais que atuam na área, modernização tecnológica de mecanismos de prevenção de delitos e violência, sistematização de dados e informações de inteligência, acesso igualitário aos serviços de justiça, incremento da cooperação jurídica internacional e reforçar políticas específicas de prevenção, controle, investigação e sanções de delinquência organizada transnacional, com foco na cooperação e compartilhamento de informações (UNASUL 20I3c).

Com relação ao estímulo de maior participação cidadã e valorização dos direitos humanos, os desafios estratégicos concentram-se, em linhas gerais, na promoção da participação dos cidadãos em programas e políticas de prevenção de delitos e violência, fortalecer instituições responsáveis por conceber políticas públicas de direitos humanos, promoção de políticas da mesma natureza, respostas efetivas a graves violações de direitos humanos, estímulo à cultura da não violência, assim como um olhar cuidadoso para as políticas penitenciárias e de reinserção e reabilitação de pessoas privadas de liberdade, adultos e jovens. Adicionalmente, há um interesse particular com a segurança cidadã das populações fronteiriças, para as quais o documento sugere fortalecimento dos órgãos responsáveis pela segurança cidadã e incentivo para a "participação e colaboração cidadã no desenho, implementação e avaliação de planos, programas e projetos de prevenção contra" a delinquência organizada transnacional das populações de zona de fronteira (UNASUL 2013b, 20).

Com o propósito de se pensar que tipo de sustentação oferece esse quadro normativo elaborado pelo CSSCJDOT para a cooperação política e o desenvolvimento de políticas públicas regionais de segurança, convém destacar os desafios estratégicos cuja linguagem sugerem construção de mecanismos convergentes para lidar com situações sobretudo envolvendo a delinquência organizada transnacional. Destacam-se os desafios estratégicos I.4 ("Promoção da criação de mecanismos para o intercâmbio de informação e inteligência referida à DOT, em conformidade com os Princípios de Reciprocidade e Confidencialidade das informações intercambiadas); 2.I ("Promoção de mecanismos de coordenação e cooperação fronteiriça e transnacional”) e 2.2 ("Promoção de um mecanismo sul-americano de cooperação policial que facilite a ação conjunta e a coordenação de ações da delinquência organizada transnacional") do plano de Coordenação de Ações contra a Delinquência Or- 
Cooperação Regional em Segurança Pública: avaliação do quadro normativo no contexto da UNASUL

ganizada Transnacional. (UNASUL 2013c, 20).

As linhas de ação/objetivos desses desafios selecionados igualmente abrem oportunidades de gerenciamento regional de questões operacionais e disseminação de informações relacionadas à delinquência organizada transnacional. Assim, propõem, dentre outros pontos, "gerar um sistema sul-americano de intercâmbio de informação e inteligência criminal para mapear rotas, modus operandi, estruturas financeiras e tendências da DOT, entre outros aspectos" (ibid., I8); "elaborar procedimentos integrados para acionar contra a DOT em geral e em zonas fronteiriças em particular, entre elas: a) ações operativas e investigativas comuns; b) guias de atuação para a detecção antecipada de situações delitivas em zonas fronteiriças; c) atividades de assistência técnica; d) adoção de convênios de colaboração recíproca a serem acionados contra a DOT" (ibid., I9) e "promover a conformação de uma instância sul-americana de cooperação policial que coordene a nível estratégico e operacional a ação conjunta contra a DOT” (ibid., 20).

Os núcleos responsáveis pela Segurança Cidadã e Justiça também formularam objetivos com potencial de se transformarem em políticas públicas de segurança regional. No que se refere ao primeiro, propõe-se a elaboração de princípios comuns para fortalecer políticas institucionais de promoção e proteção dos direitos humanos e para oferecer atenção prioritária a casos de violência contra mulher, contra população LGBT, casos de violência intrafamiliar e contra pessoas com incapacidade física ou mental. (ibid., 7-8). O grupo de trabalho dedicado à Justiça, por sua vez, prevê a elaboração de um guia de implementação de serviços de assistência jurídica gratuita (I.I.I), construir ferramentas para democratização ao conhecimento jurídico (I.2.2), estabelecer padrões mínimos em matéria de assessoramento jurídico a cidadãos dos Estados-membros que sejam processados ou condenados em outros Estados-membros (I.4.3) e para o translado dos mesmos se assim solicitado (I.4.4), promover a implementação de políticas de memória como forma de reparação e promoção da cultura de não violência (3.2.3), promover implementação de políticas de proteção a grupos que encontrem-se em situação de vulnerabilidade (3.3.I), compartilhar e implementar experiências de novos modelos de gestão penitenciária (4.I.I.), identificar princípios comuns para a elaboração de registros de casos de tortura ou tratamento ou penas cruéis, desumanos ou degradantes (4.I.5) (ibid., IO-I5).

Essas propostas, no entanto, são exceção nesse conjunto de 137 linhas de ação/objetivos elaborados no Plano de Ação do Conselho. De maneira geral, as atividades estão voltadas para troca de experiências e informações, seminários de capacitação profissional, elaborar diagnósticos nacionais sobre matérias de interesse e promover ações de cooperação e assistência técnica. 
Há, evidentemente, mérito nessas ações, especialmente devido ao potencial de socialização e imitação que a troca de experiências e informações oferece. Nenhuma dessas dinâmicas, no entanto, garante incorporação, adequação ou alteração da política de outros países; esse processo depende da combinação de um conjunto de fatores, como sugerido na seção anterior. Certamente, a maior parte das ações são direcionadas para o fortalecimento e aprimoramento das instituições nacionais em funcionamento e seus profissionais.

A tentativa de padronização de indicadores e de práticas reflete a complicada realidade da escassez de informações sistematizadas na área da segurança pública em especial e da diversidade de metodologias adotadas para categorização dos dados das áreas em questão. De qualquer forma, é sem dúvida um primeiro passo necessário para que (futuras) tentativas de adoção de políticas voltadas para propósitos comuns sejam alcançadas. E, de fato, talvez o feito mais relevante do CSCJDOT no período aqui estudada tenha sido a aprovação da Rede da UNASUL contra a Delinquência Organizada Transnacional em 24 de novembro de 2016 . Tal Rede consiste em "um mecanismo de coordenação e intercâmbio de informações para a coordenação de ações contra os delitos de caráter transnacional em atenção a competência jurídica das Forças Policiais e demais organismos competentes" (UNASUL 20I6a, Artigo I) e, embora tenha sido aprovada pelo Conselho de Ministros, ainda carece de implementação.

A maior parte das ações propostas, no entanto, foram consideradas cumpridas pelo Conselho. Tratam-se de ações tímidas, em sua grande maioria de atividades pontuais, que não desfrutam de continuidade na abordagem do conteúdo. Quase todas as atividades são originalmente oferecidas pelo Estado-membro responsável para seus nacionais, e abrem espaço para a participação de um ou dois membros dos demais Estados da UNASUL. Uma só ação também contempla uma série de linhas de ação em diversas ocasiões, o que reduz ainda mais o número de atividades direcionadas para atender uma determinada questão. Interpretado no limite mínimo que sugerem as palavras, de fato as ações realizadas cumprem os objetivos delineados, mas os termos "fomentar", "fortalecer" e "promover" demandam ações mais continuadas e estruturadas em torno das temáticas. A latitude que a linguagem utilizada oferece sugere ao que os Estados-membros produziram um Plano de Ação pragmático, considerando efetivamente quanto poderiam dispor de tempo e recursos nessas ações, e o reconhecimento da dificuldade de se concertar assertivas prioridades nas áreas de segurança pública e Justiça entre os membros da UNASUL.

Novamente, convém reforçar que se trata de um primeiro passo para a socialização e troca de informações e experiências tão necessárias para qual- 

da UNASUL

quer modelo de resposta política conjunta mais ambiciosa, seja pela implementação de políticas com direcionamento comum nos planos nacionais, seja a partir de algum tipo de coordenação oriunda do âmbito regional. A Rede da UNASUL contra DOT mostra-se uma proposta promissora a medida que eventualmente podem levar à conformação, por parte dos organismos envolvidos, sobretudo a força policial, de procedimentos compartilhados para atender padrões estabelecidos de coleta e registro de informação. Seu estágio em desenvolvimento ainda gera muitas dúvidas sobre seu funcionamento e potenciais resultados, mas sua proposta normativa demonstra possibilidades interessantes no aprofundamento da cooperação e, eventualmente, aprofundamento de políticas comuns.

Um obstáculo para a melhor compreensão das oportunidades oferecidas pelo quadro normativo criado no âmbito do CSCJDOT é o limitado acesso a informação de conteúdo substantivo das ações. Os instrumentos utilizados para diagnósticos e coleta de informações sobre delitos e violência, por exemplo, foram incluídos nos documentos originais como anexos, não disponibilizados para o público ${ }^{\text {II }}$. O anexo seria somente o projeto de atividade, ou a proposta de questionário no seu original, que, embora fosse de muito maior valia analítica se o acesso às respostas fossem publicizados, em si, exclusivamente as escolhas acerca dos temas a serem tratados nos questionários e conteúdo das oficinas e workshops oferecidos contribuiriam significativamente para compreender as prioridades possivelmente preferidas em termos de temas e tratamento de matérias de segurança pública no contexto regional. Acesso às respostas permitiria identificar o grau de convergência entre os países em termos de procedimentos, desenho de políticas e prioridades estratégicas para a área. Talvez isso reflita a própria imaturidade dos sistemas políticos dos países da América do Sul na construção e transparência de suas atividades e decisões envolvendo a área segurança pública coordenadas no nível federal.

Associada à falta de transparência em torno de conteúdos apreciados nas discussões e instrumentos utilizados pelo CSSCJDOT, uma outra faceta pouco democratizante dos processos do Conselho reside na participação dos atores nos debates e reuniões. Duas características podem ser constatadas: a primeira, com relação à ausência de participação da sociedade civil; a segunda referente à disparidade de autoridades decisórias nos encontros. Em nenhum dos encontros em que foram divulgados os participantes nesse período de

\footnotetext{
II Tratam-se da primeira, da segunda e da terceira reunião de cada um dos grupos temáticos, todas realizadas em 20I6, em que foi dividido o Conselho: Grupo de Coordenação de Ações contra a Delinquência Organizada Transnacional, Grupo de Trabalho de Justiça e o Grupo de Trabalho de Segurança Cidadã. Available at http://docs.unasursg.org/all-documents, accessed November 24, 2017.
}

80 Austral: Revista Brasileira de Estratégia e Relações Internacionais v.7, n.14, Jul./Dez. 2018 
20I3-20I7 atores não-governamentais estiveram presente (UNASUL 20I4d). Curioso, uma vez que diversas das iniciativas no plano das linhas de ação/objetivos e desafios estratégicos são voltados para fortalecer ou promover maior participação cidadã nas políticas e programas de combate a delitos e violência. Não só isso reforça a hipótese anterior de que a abertura ao debate para a sociedade ainda carece de incentivos institucionais e políticos na área da segurança, como inibe um mecanismo que se mostrou relevante para a disseminação e incorporação de políticas regionais na arena nacional: a atuação de grupos da sociedade civil enquanto agentes de interesse, que pressionam e influenciam autoridades locais a discutirem e definirem políticas públicas.

A segunda questão, referente aos atores governamentais indicados a participar dos encontros, possui duas dimensões. Em primeiro lugar, convém mencionar a diversidade da origem institucional dos atores que participam das reuniões da Instância Executiva. São profissionais que atuam nos equivalentes, no Brasil, ao Ministério da Justiça e Segurança Pública, Ministério da Defesa, Ministério das Relações Exteriores, Polícia Federal, Ministério do Planejamento, Procuradoria Geral do Estado, Ministério dos Direitos Humanos e a Agência Brasileira de Inteligência (UNASUL 20I3a, 20I3b, 20I3c). Trata-se, portanto, de um contexto complexo de coordenação pelo número de agências envolvidas no nível intragovernamental e intergovernamental. Além disso, diferem bastante os cargos ocupados pelos participantes em cada uma dessas instituições. Alguns Estados-membro - que variam de reunião para reunião - enviam representantes com maior autoridade para os encontros, enquanto outros representantes ocupam cargos mais baixos na escala hierárquica, tornando o processo decisório e o expediente de andamento dos procedimentos e atividades mais moroso. Outro dado é que nem sempre as mesmas instituições de um mesmo país participam dos encontros. Há menos que haja consistente comunicação interagências, há grandes chances de haver lacuna no conhecimento sobre o desenvolvimento das atividades realizadas no âmbito do Conselho.

No entanto, é preciso salientar que o número de documentos que apontam os participantes dos encontros, seja com relação aos grupos de trabalho quanto da Instância Executiva, é consideravelmente baixo. Depois de 20I4, nenhum dos documentos disponíveis no repositório digital da UNASUL apresenta anexos, espaço em que se listava nos documentos até esse ano o nome e o cargo ocupado pelos representantes. Para os grupos de trabalho, somente dois documentos estão disponíveis com a mencionada informação entre 20I3-20I7; para a Instância Executiva, somente três. Tratam-se, portanto, de inferências com base em informação consideravelmente limitada.

Embora o Plano de Ação contenha significativas atividades a serem 
Cooperação Regional em Segurança Pública: avaliação do quadro normativo no contexto da UNASUL

desenvolvidas e tenha sido elaborado para um período de 5 anos, os encontros tanto de grupo de trabalhos quanto da Instância Executiva são relativamente escassos. De acordo com os documentos disponíveis até o presente momento, a Instância Executiva se reuniu em onze ocasiões. Os Grupos de Trabalho variaram bastante de ano para ano. Em 20I4, por exemplo, o Grupo de Trabalho de Justiça produziu três atas de encontros, o mesmo para 20I6; os Grupos de Trabalho dedicados à Segurança Cidadã e DOT produziram uma ata cada para o ano de 2014 e três para o ano de 20I6. Existe a possibilidade, sem dúvida, de que encontros tenham ocorrido sem nenhum registro. O ano de 2015 é excepcional por haver somente um registro de encontro: a III Reunião de Ministros do CSSCJDOT. O documento aborda três propostas de coordenação e adoção de práticas políticas comuns; somente uma delas foi aprovada de acordo com os documentos disponíveis: a Rede UNASUL Contra DOT ${ }^{\text {I2 }}$ (UNASUL 20I5).

O número reduzido de reuniões e a diversidade de atores e agências que participam dos encontros sugere, em um primeiro olhar, pouco prioridade da organização e dos Estados no tratamento da cooperação regional na área da segurança pública. Contribui para isso o fato de que diversos dos questionários enviados, sobretudo relacionados a diagnósticos de políticas locais que permitiriam aprofundamento do diálogo, não foram respondidos por todos os Estados quando solicitados, muitas vezes em mais de uma ocasião formalmente. Como mencionamos anteriormente, nenhum dos questionários solicitados é de domínio público, mas considerando a diversidade e abrangência dos temas tratados (por exemplo, Questionário de Diagnóstico Regional I.I.I Estado da Situação da DOT: Mecanismos estatais de prevenção, investigação e sanção; Diagnostico Regional I.4.I Questionário do Sistema Sul-Americano de Intercâmbio de Informação de Inteligência Criminal; Questionário sobre Guia de Atuação para a Detenção Preventiva de Pessoas em Zonas de Fronteira, dentre outros (UNASUL 20I6b), a tarefa de conseguir informações adequadas sobre o assunto não deve de fato ser de fácil execução. Demanda um número considerável de atores, boa coordenação entre agências, dados sistematizados disponíveis sobre a questão. Esses seriam obstáculos de natureza burocrática, mesmo que haja vontade política.

Antes de passarmos para a próxima seção, dois aspectos finais devem ser mencionados com relação à atuação e construção do quadro normativo da CSSCJDOT. O primeiro diz respeito a tentativa de articulação das iniciativas voltadas para tratar a delinquência organizada transnacional com o Conselho Sul-Americano sobre o Problema Mundial das Drogas. A sobreposição de

I2 As outras duas propostas são a criação de Regras Mínimas da UNASUL sobre Acesso à Justiça e a criação do Centro de Estudos Estratégicos contra a Criminalidade Organizada Transnacional (UNASUL 20I5). 
funções e interesses é evidente, e o CSSJDOT desde suas discussões iniciais apontou para a necessidade de se estabelecer ação coordenada com esse organismo, por determinação do próprio Conselho de Chefas e Chefes de Estado e Governo da UNASUL quando de sua criação, em $2012^{13}$. Uma reunião entre os Presidentes Pro-Tempore dos dois Conselhos foi realizada em julho de 20I4, no qual se acordou sobre a criação de grupos ad hoc para desempenharem ações de acordo com suas singularidades, de modo a garantir a complementaridade de esforços nos temas coincidentes de interesse e explicitados nos objetivos específicos de cada um dos Conselhos. Giram em torno da promoção da cooperação judicial, policial e de unidades de inteligência financeira, promover o intercâmbio de experiências e boas práticas, contribuir para o fortalecimento da capacidade institucional dos organismos competentes e a formação e capacitação de agentes envolvidos (UNASUL 20I4c). Não houve posterior menção a ações conjuntas entre esses dois organismos. A outra sugestão de aproximação institucional foi com organismos de similar função da União Europeia (UNASUL 20I5), também sem indicações posteriores sobre seu andamento.

O último ponto a ser aqui discutido refere-se à definição dos conceitos, ou melhor, a ausência de clara definição dos conceitos que subsidiam a delimitação do campo de atuação e interesse do Conselho. Em momento algum, nem em seu estatuto, nem nos demais documentos produzidos ao longo dos últimos 5 anos, o Conselho oferece uma definição do que seria "segurança cidadã" ou "Delinquência Organizada Transnacional". O que se infere, por indicação das justificativas para a criação do CSSCJDOT e do Conselho sobre o problema das drogas como instâncias independentes e autônomas em suas atribuições e funções, é que tais conceitos tomam como base as elaborações adotadas pela Organização das Nações Unidas, que cuidou de definir os referidos termos, assim como considerou prudente criar agências distintas para lidar com o problema das drogas e da DOT.

Em linhas gerais, pode-se resumir as atividades do Conselho como relativamente pragmáticas, à medida que estabelece linhas de ação/objetivos que possam ser, na sua interpretação mais minimalista, atendidas por atividades já desenvolvidas no âmbito nacional, sem demandar excessivo aporte de recursos, capital humano e modificações no desenho institucional ou de

I3 Foram definidos como áreas temáticas comuns a I) "[r]edução da oferta de drogas, incluindo o tráfico, o cultivo, a comercialização, a distribuição, a produção e a fabricação de ilícitos que afetem a segurança cidadã ou constituam manifestações de Delinquência Organizada Transnacional; 2) Ações contra os delitos conexos e atividades vinculadas ao problema mundial das drogas tais como o desvio de precursores e insumos químicos e a lavagem de dinheiro que afetem a segurança cidadã ou constituam manifestações da Delinquência Organizada Transnacional" (UNASUL 20I3c, anexo V). 

da UNASUL

políticas nacionais; difusa, pois contempla um número excessivo de temáticas, cuja abrangência torna sua realização, de forma satisfatória em todas as frentes, virtualmente inalcançável no período de tempo estipulado; e em consequência desses dois últimos pontos, uma atuação com avanços pouco memoráveis, à exceção, talvez, da decisão de criar a Rede da UNASUL contra a Delinquência Organizada Transnacional. Vale lembrar, no entanto, que as especificações do funcionamento da rede ainda estão em aberto, assim como a quantidade de recursos a ser destinada para sua manutenção.

\section{Considerações Finais: perspectivas e cenários a cooperação regional na área da segurança pública na América do Sul}

Para qual direção o quadro normativo construído no âmbito da CSSCJDOT indica para se pensar a possibilidade de cooperação política na área de segurança pública regional, em um primeiro momento, e a construção de políticas públicas comuns, coordenadas regional ou nacionalmente, para o mesmo tema? Gostaríamos de especular em três direções.

O primeiro ponto refere-se ao conteúdo substantivo das políticas e ações sugeridas pelo CSSJDOT. Como vimos na seção acima, tratam-se de ações propositivas, que focam em fortalecer instituições, promover programas e projetos e capacitar profissionais dos governos nacionais, com poucas iniciativas realmente voltadas para iniciativas que demandem adequações político-institucionais para atenderem os preceitos conceituais estabelecidos na região. A manutenção desse padrão de atuação permitirá, por um lado, a continuidade da instituição com um mínimo de relevância no contexto regional, oferecendo oportunidades, ainda que aparentemente bastante limitadas, de socialização e transferência de conhecimento sobre as questões em pauta. A eventual manutenção desse contato institucionalizado e permanente pode permitir que pontos de convergência específicos surjam entre um número menor de Estados-membros, que poderá entrar em acordos de coordenação e definições de desenhos políticos comuns de forma independente da UNASUL. De fato, o grande número de atores envolvidos, com consideráveis assimetrias estruturais, pode dificultar a cooperação em nível mais aprofundado.

Por outro lado, é preciso reconhecer que, no que diz respeito às mazelas de segurança pública, há bastante convergência entre os países da região. Um crescente aumento no número de homicídios na maior parte deles, denúncias de utilização excessiva do uso da força por parte da polícia, pouca participação da sociedade civil nos processos e decisões relacionadas à segurança pública, parcelas significativas da população em situação de vulnerabilidade, 
os impactos da delinquência organizada transnacional na violência social, falência do sistema de justiça criminal; em outras palavras, uma dinâmica com forte componente estrutural (Cerqueira, Lobão and Carvalho 2005). Definir com clareza os conceitos envolvidos na elaboração das políticas de segurança pública, e sua tentativa de compatibilização, aparece como condição necessária para qualquer avanço consistente e significativo nos planos nacional e regional. Assim, o esforço de contextualizar a definição de "Delinquência Organizada Transnacional" e "Segurança Cidadã" consiste em um passo importantíssimo do processo.

Sem dúvida, trata-se de uma tarefa bastante desafiadora. Na realidade, antes da própria criação do CSSCJDOT, em 20II, houve uma iniciativa para se discutir e definir conceitualmente os termos Segurança e Defesa Regional, assim como de se criar um Protocolo de Paz, Segurança e Cooperação na UNASUL. (UNASUL 20IIa, 20IIb, 20IIc). A empreitada não foi bem-sucedida e as discussões não avançaram - ao menos não há registro público de que tenham tido continuidade. Mas tratar a questão é essencial. Se não for possível determinar definições conceituais holísticas sobre segurança, subitens e tópicos específicos podem ser objeto de discussão e consenso, permitindo que alguma das diversas áreas que o CSSCJDOT abarca contribuam para melhores concepções de ações conjuntas e/ou comuns. Parece pouco promissor o aprofundamento das relações regionais para segurança pública se o CSSCDOT optar por não realizar esse diálogo, como aparentemente o fez até o momento.

Reflexo disso é que questões centrais da discussão de políticas públicas no plano regional foram deixadas de fora, ou tratadas no mínimo marginalmente, pelos eixos temáticos, desafios estratégicos e linhas de ação/ objetivos do Conselho. Independentemente das possibilidades (ou impossibilidade) de se estabelecer linhas de ação ambiciosas, de difícil consecução, esses temas poderiam ser contemplados nas próprias propostas de troca de experiências e boas práticas, seminários ou atividades de fomento do conhecimento de mesma natureza. Duas chamam atenção. A primeira é o tema da reforma da polícia; o segundo, "um enfoque integrado de gestão, baseado no planejamento científico, focado na prevenção e no tratamento das causas que levam ao crime" (Cerqueira, Lobão and Carvalho 2005, I3). Adicionalmente, pode-se mencionar uma terceira questão, central para a discussão das ameaças transnacionais de segurança: as particularidades da relação entre o índice de homicídios e a Delinquência Organizada Transnacional. Dessa forma, há um descompasso entre as preocupações de políticas públicas de segurança no nível local, além do nacional. Mas inegavelmente, a esfera local, como sugere a própria preocupação do Conselho com a participação, não pode ser 
Cooperação Regional em Segurança Pública: avaliação do quadro normativo no contexto da UNASUL

negligenciada, sobretudo se pretende-se identificar os impactos reais da DOT sobre a segurança cidadã.

No que diz respeito à última, o CSSCJDOT, na Reunião de Ministros de outubro de 2013 , determinou como prioridade temática o crime de lavagem de dinheiro (UNASUL 2013c) ${ }^{14}$. Não se demonstrou nos documentos, no entanto, nenhum tratamento diferenciado para a questão, seja no que diz respeito a ações quanto a discussões sobre procedimentos e/ou dinâmicas particulares.

A segunda perspectiva a ser considerada é a evolução do sistema de trocas de informações, bastante promissora no projeto da Rede da UNASUL contra a DOT. A sistematização da informação e a padronização da coleta de dados coloca-se hoje como um empecilho para avaliações mais precisas sobre as características e o status da segurança pública no Brasil, por exemplo (Cerqueira, Lobão and Carvalho 2005). Se há divergências em função da autonomia de que gozam as unidades federativas em determinar seus critérios e procedimentos de registro de delitos e crimes de violência, as discrepâncias entre os países prometem ser consideráveis. O CSSCJDOT reconhece isso, em grande medida, ao instigar a elaboração de um conjunto de diagnósticos sobre realidades locais associadas à segurança cidadã, justiça e delinquência organizada transnacional. Caso haja investimento nesse tipo de prática, as possibilidades de padronização para mais efetiva troca de informações soam bastante promissoras. Iniciativas bem-sucedidas nesse sentido demandarão esforços coletivos no âmbito dos governos nacionais e, portanto, indispensável vontade política para que ocorram. Mas podem contribuir muito tanto para a criação de políticas direcionadas a fins comuns entre os países da região, quanto para se identificar novas explicações para os crimes de natureza transnacional, seu impacto sobre a segurança doméstica dos países sul-americanos e modelos de prevenção da violência nessas circunstâncias. Novas metodologias de coleta e armazenamento de dados voltados para prevenção, como sugere a literatura internacional sobre segurança pública (Cerqueira, Lobão and Carvalho 2005), no entanto, tendem a se beneficiar da participação cidadã nas diversas etapas do processo de gerenciamento e definição das políticas públicas. Não está claro se a Rede será um instrumento de acesso público, ao menos em parte da sua informação, mas seria um elemento importante para a efetividade das atividades de troca de informação padronizada. A sociedade civil funciona como um instrumento de legitimação dos processos, detentor de conhecimento especializado e proximidade das demandas da

I4 Ver também http://www.justica.gov.br/sua-protecao/cooperacao-internacional/atuacaointernacional-2/foros-internacionais/uniao-das-nacoes-sulamericanas-unasul, acesso em 4 de dezembro de 2017 .

86 Austral: Revista Brasileira de Estratégia e Relações Internacionais v.7, n.14, Jul./Dez. 2018 
sociedade, ao menos de parte da sociedade ${ }^{15}$. Como argumentado ao longo do texto, o histórico do CSSCJDOT na publicização dos conteúdos discutidos de debates entre membros que participam dos encontros é restrito. Pode ser resultado de deficiências burocráticas, mas em algumas ocasiões, como no caso da elaboração da Cartilha de Boas Práticas em Matéria de Reinserção Social de Pessoas Privadas de Liberdade e Políticas Penitenciárias, deliberadamente definida como uma atividade sem difusão pública pela Instância Executiva do Conselho (UNASUL 20I4b).

Por fim, a terceira perspectiva a ser debatida refere-se à institucionalidade regional em torno da segurança pública, isto é, trata mais amplamente da institucionalidade dos processos de regionalização em si. Historicamente, na América do Sul, a incorporação de temáticas distintas da integração comercial tiveram seu maior impulso com a onda de governos de esquerda - ou centro-esquerda - que assumiram o poder nos países da região. Embora outras temáticas tenham sido objeto de apreciação em momentos anteriores a esse, como no caso do Mercosul, foi efetivamente com esse movimento que se intensificou sua a institucionalização no âmbito regional. A criação da UNASUL em 2008 consiste talvez no exemplo mais evidente deste acolhimento e reconhecimento da relevância da dimensão regional como esfera legítima para o tratamento de matérias previamente menos propensas a serem pauta da agenda externa ${ }^{16}$. O futuro de um envolvimento mais comprometido com a cooperação regional na área de segurança pública e, eventualmente, com a construção de políticas regionais de segurança pública, assim como a forma que irão assumir essas políticas, portanto, parecem estar de alguma forma atreladas aos rumos e características mais amplas impressas pelos governos aos processos de regionalização.

A análise dos instrumentos normativos lança luz em uma parcela muito modesta do processo de cooperação regional de segurança públicas. Como discutido na segunda seção desse texto, um universo grande de variáveis se combinam em arranjos complexos para explicar os resultados de interações permeadas por disputas de interesses, ideias, recursos e atores que podem levar a formulação de uma política pública ou um acordo de cooperação com fins comuns. No entanto, o quadro normativo dentro do qual esses

I5 Não se pretende aqui sugerir a ausência de disputas acerca de percepções políticas entre os diversos atores da sociedade civil, tampouco desconsiderar discordâncias sobre o conceito de sociedade civil e a pluralidade de suas manifestações. Somente levantar o ponto sobre um tipo de representação institucionalizada de interesses da sociedade.

I6 Esse foi o caso das políticas públicas sociais regionais, que tiveram maior impulso nesse período em que os governos nacionais forma mais influenciados por partidos de esquerda e centro-esquerda (Hartlapp 20I4). 
atores estabelecem suas lutas - em si, também objeto de disputas - é o ponto de partida para se compreender os limites e as possibilidades oferecidas pelas circunstâncias. O futuro da segurança pública regional é incerto, mas os números desanimadores do aumento da criminalidade e da violência nos países da região na última década deixam a esperança de que a regionalização seja uma alternativa eficiente para se começar a sanar o problema.

\section{REFERÊNCIAS}

Adler, Emanuel and Michael Barnett, eds. I988. Security Communities. Cambridge: Cambridge University Press.

Bianculli, Andrea C. and Andrea R. Hoffmann. 2016. "Regional Organizations and Social Policy: The Missing Link." In Regional Organizations and Social Policy in Europe and Latin America. A Space for Social Citizenship?, edited by Andrea C. Bianculli and Andrea R. Hoffmann, I-22. New York/Hampshire: Palgrave MacMillan.

Buzan, Barry, Ole Waever and Jaap de Wilde. 1997. Security. A New Framework for Analysis. UK: Lynne Rienner Publishers.

Buzan, Barry and Ole Waever. 2003. Regions and Powers: the structure of international security. Cambridge: Cambridge University Press.

Cerqueira, Daniel, Waldir Lobão and Alexandre X. Carvalho. 2005. "O Jogo dos Sete Mitos e a Miséria da Segurança Pública no Brasil." Texto para Discussão no 1144. Rio de Janeiro: IPEA (Instituto de Pesquisa Econômica Aplicada), December: I-30.

Espino, Alma. 2016. "Work and Employment in Mercosur from a Gender Perspective: Challenges and Public Policies." In Regional Organizations and Social Policy in Europe and Latin America. A Space for Social Citizenship?, edited by Andrea C. Bianculli and Andrea R. Hoffmann, I39-I62. New York/Hampshire: Palgrave MacMillan.

Hartlapp, Miriam. 20I6. "Regulating Social Policy in the EU and Mercosur: Patterns and Developments in Social Security and Related Areas." In Regional Organizations and Social Policy in Europe and Latin America. A Space for Social Citizenship?, edited by Andrea C. Bianculli and Andrea R. Hoffmann, 92-II6. New York/Hampshire: Palgrave MacMillan.

Mercado Comum do Sul (MERCOSUL). 2006. "Acordo Quadro sobre Cooperação em Matéria de Segurança Regional entre os Estados 
Partes do MERCOSUL, a República da Bolívia, a República do Chile, a República da Colômbia, a República do Equador, a República do Peru e a República Bolivariana da Venezuela”. Córdoba, July 20.

Perrotta, Daniela and Mariana Vazquez. 20ıо. "El Mercosur de las Políticas Públicas Regionales. Las Agendas em Desenvolvimento Social e Educação." Documento de Trabajo oıo. Uruguai: CEFIR - Centro de Formación para la Integración Regional: 15 -7I.

Perrotta, Daniela. 20I6. "Mercosur's Regional Policies in Higher Education: The Diffusion of Accreditation and Quality Assurance Policies." In Regional Organizations and Social Policy in Europe and Latin America. A Space for Social Citizenship?, edited by Andrea C. Bianculli and Andrea R. Hoffmann, I85-205. New York/Hampshire: Palgrave MacMillan.

Radaelli, Claudio M. 2003. "The Europeanization of Public Policy". In The Politics of Europeanization, edited by Kevin Featherstone and Claudio M. Radaelli, 27-56. Oxford: Oxford University Press.

Souza, Celina. 2007. "Estado da arte da pesquisa em políticas públicas." In Políticas Públicas no Brasil, organized by Gilberto Hochman, Marta Arretche and Eduardo Marques, chapter 2. Rio de Janeiro: Editora FIOCRUZ. E-Book.

Union of South American Nations (UNASUL). 2008a. "Tratado Constitutivo da União de Nações Sul-Americana”. May 23.

2008b. Decisão para o Estabelecimento do Conselho de Defesa Sul-Americano da UNASUL/Estatuto do Conselho de Defesa Sul-Americano. December I6.

20iıa. "IV Reunião do Grupo de Trabalho Encarregado de Elaborar o Protocolo de Paz, Segurança e Cooperação da UNASUL". Informe da Presidência, July 7 -8.

20Irb. "II Seminário Sul-Americano Visão de Enfoques Conceituais de Defesa, Riscos e Ameaças a Região - Elementos Coincidentes da Mesa nffl 2. 'Caracterização da realidade em matéria de segurança e defesa regional: ameaças e riscos'. Conselho de Defesa Sul-Americano, Caracas, September 6-8.

20I2a. "Estatuto do Conselho Sul-Americano em Matéria de Segurança Cidadã, Justiça e Coordenação de Ações contra a Delinquência Organizada Transnacional”. November 29-30.

20I2b. "UNASUL e a Cooperação na Luta contra o Crime Organizado Transnacional e os Delitos Transfronteiriços.", Centro de Estudos Estratégicos de Defesa do Conselho de Defesa Sul- 
Cooperação Regional em Segurança Pública: avaliação do quadro normativo no contexto da UNASUL

Americano.

2013a. "Ata da I Reunião da Instância Executiva do Conselho Sul-Americano em Matéria de Segurança Cidadã, Justiça e Coordenação de Ações contra a Delinquência Organizada Transnacional.", February 28 - March oI.

20I3b. "Ata da II Reunião da Instância Executiva do Conselho Sul-Americano em Matéria de Segurança Cidadã, Justiça e Coordenação de Ações contra a Delinquência Organizada Transnacional.", April 8-ıo.

20I3c. "Ata da III Reunião da Instância Executiva do Conselho Sul-Americano em Matéria de Segurança Cidadã, Justiça e Coordenação de Ações contra a Delinquência Organizada Transnacional.", May 20 -2I.

. 20I4a. "Ata da II Reunião do Grupo de Trabalho de Justiça. Conselho Sul-Americano em Matéria de Segurança Cidadã, Justiça e Coordenação de Ações contra a Delinquência Organizada Transnacional.", April 23-24.

20I4b. "Ata da VI Reunião da Instância Executiva do Conselho Sul-Americano em Matéria de Segurança Cidadã, Justiça e Coordenação de Ações contra a Delinquência Organizada Transnacional.", June 25 -26.

20I4c. "Ata da Reunião entre a Presidência Pro-Tempore do Conselho Sul-Americano sobre o Problema Mundial das Drogas e a Presidência Pro-Tempore do Conselho Sul-Americano em Matéria de Segurança Cidadã, Justiça e Coordenação de Ações contra a Delinquência Organizada Transnacional.", July 7-8.

. 20I4d. "Ata da III Reunião do Grupo de Trabalho Especializado de Justiça do Conselho Sul-Americano em Matéria de Segurança Cidadã, Justiça e Coordenação de Ações contra a Delinquência Organizada Transnacional.”, September 8-9.

20I5. "Ata da III Reunião de Ministros do Conselho SulAmericano em Matéria de Segurança Cidadã, Justiça e Coordenação de Ações contra a Delinquência Organizada Transnacional da UNASUL", October 30.

20I6a. "UNASUR/CMRE/RESOLUCION Nffl I5/20I6

- Criação da Rede UNASUL contra a Delinquência Organizada Transnacional entre os Organismos dos Estados Membros da UNASUL.", November, 24.

20I6b. "Ata da IX Instância Executiva do Conselho Sul-

90 Austral: Revista Brasileira de Estratégia e Relações Internacionais v.7, n.14, Jul./Dez. 2018 
Americano em Matéria de Segurança Cidadã, Justiça e Coordenação de Ações contra a Delinquência Organizada Transnacional.", November, 24-25.

Van Langenhove and Stephen Kingah. 20I6. In Regional Organizations and Social Policy in Europe and Latin America. A Space for Social Citizenship?, edited by Andrea C. Bianculli and Andrea R. Hoffmann, 23I-250. New York/Hampshire: Palgrave MacMillan.

Yeates, Nicola. 20I4. "The Socialization of Regionalism and The Regionalization of Social Policy: Contexts, Imperatives, and Challenges". In Transformations in Global and Regional Social Policies, edited by Alexandra Kaasch and Paul Stubbs , I7-43. Hampshire: Palgrave Macmillan.

\section{RESUMO}

Esse artigo tem por objetivo avaliar o quadro normativo no qual se apoia as práticas cooperativas na área de segurança pública regional com base nas atividades desenvolvidas pelo Conselho Sul-Americano em Matéria de Segurança Cidadã, Justiça e Coordenaação de Ações contra a Delinquência Organizada Transnacional da UNASUL. O texto discute as diferenças e aproximações entre as concepções de cooperação e políticas públicas, analisa os documentos produzidos no âmbito do Conselho e apresenta limitações, obstáculos e oportunidades identificadas a partir da análise dos documentos no que diz respeito à cooperação regional na área da segurança pública.

\section{PALAVRAS-CHAVE}

Cooperação regional, segurança regional, UNASUL. 